\title{
Pretargeted Radioimmunotherapy
}

National Cancer Institute

\section{Source}

National Cancer Institute. Pretargeted Radioimmunotherapy. NCI Thesaurus. Code

C116541.

A technique used to improve the efficacy of radioimmunotherapy that targets the tumor with both an antibody construct and a radiolabeled hapten prior to the administration of radiation therapy. 